\title{
PROPOSTAS PEDAGÓGICAS COMPROMETIDAS COM A CLASSE TRABALHADORA: ENSINO MÉDIO INTEGRADO E COMPLEXOS DE ESTUDOS $^{1}$
}

\section{PEDAGOGICAL PROPOSALS COMMITTED TO THE WORKING CLASS: INTEGRATED HIGH SCHOOL AND STUDY COMPLEXES}

\author{
PEREIRA, Noemi Ferreira Felisberto ${ }^{2}$ \\ SOLDA, Maristela ${ }^{3}$
}

\begin{abstract}
RESUMO
O presente artigo sintetiza duas propostas de educação que visa à formação do sujeito na perspectiva omnilateral, ambas pioneiras no Brasil. A primeira é a proposta implantada na Rede Estadual de Educação paranaense que, mesmo antes de normativa federal que the desse suporte, implantou a integração entre ensino profissional e educação média. A segunda foi desenvolvida nas escolas do Movimento dos Trabalhadores Rurais Sem Terra (MST), também no Paraná. Intitulada Complexos de Estudo, é baseada na Pedagogia Russa. A partir de pesquisa bibliográfica e documental, verificamos que a categoria trabalho enquanto atividade criadora é fundamental para uma proposta educacional que tem no horizonte a formação para emancipação do gênero humano.
\end{abstract}

PALAVRAS-CHAVE: Educação integrada, Formação humana, Trabalho, MST.

\section{ABSTRACT}

The present article summarises two proposals of education that aim at the formation of the subject in an omnilateral perspective, both pioneers in Brazil. The first is the proposal implemented in the Paraná State Education System, which, even before federal regulations that supported it, implemented the integration between professional and middle education. The second one was developed in schools of the Landless Rural Workers Movement (MST), also in Paraná. Named "Study Complexes", it is based on Russian Pedagogy. Based on bibliographical and documentary research, we found that work as a creative activity is fundamental for an educational proposal which aims at a formation for the emancipation of the human race.

KEYWORDS: Integrated education; Human formation, Work, MST.

\footnotetext{
${ }^{1}$ Agradecemos todos os diálogos e interlocuções realizadas nas defesas das duas dissertações que originaram este artigo. Em especial ao professor e pesquisador Gaudêncio Frigotto, que estimulou o processo de escrita deste.

2 Mestre em Sociedade, Cultura e Fronteira - UNIOESTE. Técnica em Assuntos Educacionais na Universidade Federal da Integração Latino-Americana - UNILA. e-mail: noemi.ferreira@unila.edu.br

${ }^{3}$ Mestre em Sociedade, Cultura e Fronteira - UNIOESTE. Professora da Rede Pública Municipal de Cascavel/PR. e-mail: maristelasolda@hotmail.com
} 


\section{INTRODUÇÃO}

Uma educação calcada no polo trabalho enquanto dimensão ontocriativa tem a compreensão que a função mediadora da categoria trabalho não está restrita à resposta aos fatores econômicos, antes tem a compreensão de que ele é o fundamento do ser social (PEREIRA, 2017, p. 137).

A perspectiva de construção de uma nova sociedade, mais justa e inclusiva, faz com que nós, enquanto educadores com consciência de classe, prossigamos na luta pela transformação da escola convencional (SOLDA, 2017, p. 114).

As epígrafes ${ }^{4}$ acima, oriundas de pesquisas com objetos próprios, explicitam a preocupação em pensar a educação para a classe trabalhadora. Uma educação que tenha a potencialidade de instrumentalizar o educando para que seja sujeito de seu próprio destino. Uma educação para emancipação do gênero humano. É nesse sentido que convergiram duas pesquisas relacionadas às propostas pedagógicas que têm no horizonte a formação integral do estudante. Uma buscou compreender, entre outras categorias, a concepção de ensino médio integrado à educação profissional, a partir da análise da relação capital-trabalho. Essa vertente foi efetivada na educação convencional do estado do Paraná antes mesmo que a legislação nacional Ihe conferisse legalidade. A outra pesquisa desenvolveu reflexões sobre a proposta pedagógica Complexos de Estudo, produzida pelos educadores da escola do Movimento dos Trabalhadores Sem Terra (MST), junto com o Setor de Educação do MST e com as universidades públicas do Paraná em 2013.

Da junção dessas duas discussões é que resultou este artigo que tem como objetivo compartilhar as experiências pioneiras de implantação/discussão do ensino médio integrado à educação profissional e da proposta pedagógica dos Complexos de Estudos implementada nos acampamentos e assentamentos do MST desde 2013, ambas no estado do Paraná.

A análise está embasada na perspectiva da totalidade material, que permite ao sujeito enxergar o objeto presente como síntese de múltiplas determinações. As bibliografias que dão suporte às discussões são Frigotto (1999, 2011), Ciavatta (2009)Grasmci (2001), Freitas (2011), Shulgin (2013), Pistrak (2009, 2011), entre outros. Da pesquisa documental destacamos as Diretrizes e Bases da Educação Profissional no Paraná, os Decretos no 2.208/97 e no 5154/04, a Proposta

\footnotetext{
${ }^{4}$ Os textos citados compõem as dissertações: "Trabalho, Capital e Educação: análises comparadas a partir dos Cursos de Agroecologia IFPR e ITEPA" e "Núcleo Setorial e os aspectos interdisciplinares na Proposta Pedagógica Complexos de Estudo", defendidas em abril de 2017.
} 
Pedagógica Complexos de Estudos, os Cadernos de Educação do MST e as memórias das Escolas do MST.

O artigo está organizado da seguinte forma: inicialmente discorremos sobre a categoria ensino integrado seus pressupostos e suas implicações para uma formação na perspectiva da formação humana. Em seguida apresentamos como a proposta de ensino integrado se efetivou no estado do Paraná que foi percussor no âmbito formal da educação nessa direção. Em um terceiro momento, dissertamos sobre os Complexos de Estudos que se apresenta como uma proposta pioneira e ainda mais avançada na luta pela transformação social.

\section{A ConCEPÇÃo de EnSINo InTEGRADO}

Ciavatta e Ramos (2012) ponderam que o Ensino Médio Integrado deriva do termo formação integrada, sendo de elaboração recente aqui no Brasil. Porém, salientam as autoras, o termo tem uma origem remota na educação socialista, na concepção de educação politécnica ou tecnológica e origem recente, na segunda metade dos anos 1980, nas lutas do Fórum Nacional em Defesa da Educação Pública. Todavia, em termos de legislação, a categoria foi incorporada pelo decreto no 5.154/2004 e, posteriormente, na LDB/1996 pela Lei no 11.741/2008 que incluiu ao artigo 36 a possibilidade do Ensino Médio fornecer a formação geral e preparar o educando para o exercício de profissões técnicas.

Assim, o termo integrado primeiramente nos reporta à oferta do Ensino Médio articulado ao ensino profissional garantindo, conforme o próprio texto legal, que a formação geral não seja substituída nem minimizada pela formação profissional. Entretanto, para os educadores e lutadores em busca da construção de uma nova sociedade, o sentido da expressão é muito mais amplo. Está muito ligado ao intento de vencer a dualidade no campo educacional: uma educação para formar dirigentes e outra de cunho instrumental para formar dirigidos. Nesse sentido, é a busca pela constituição de uma escola unitária arrazoada por Gramsci (2001) como aquela de cultura geral, humanista, formativa, que equilibra de modo justo o desenvolvimento das capacidades de trabalhar manualmente e o desenvolvimento das capacidades de trabalho intelectual. Isso contrapõe a educação baseada em classes sociais e busca formar todos para serem líderes ou liderados de uma nova sociedade baseada na justiça social.

Nessa perspectiva, a concepção de ensino médio integrado vai tomando contornos conceituais mais profundos, pois está ligada a concepções de mundos, de educação, de homem, de sociedade, divergentes, dado o solo material em que se desenvolve o debate. Nesse sentido, defendemos a integração calcada no materialismo histórico dialético, que é a luta por uma educação de qualidade como direito de todos. Uma educação não 'rotulada', não 'destinada', enfim, uma educação postulada por Gramsci (2001) como "desinteressada" que propicie ao educando o 
acesso aos conhecimentos acumulados pela sociedade e lhe forneça elementos para compreender a sociedade, as relações sociais, podendo, assim, intervir na realidade em que ele está inserido.

Esse é o sentido que os educadores progressistas e os trabalhadores deram desde as primeiras discussões sobre a categoria a partir da década de 80 . Partindo desse pensamento, Ramos (2008) pontua três sentidos - que se complementam para análise da categoria integração: a) a formação omnilateral; b) a indissociabilidade entre educação profissional e educação básica; c) a integração como uma totalidade.

A formação omnilateral expressa a concepção de formação humana que tem o trabalho enquanto atividade criativa e explicitadora das potencialidades humanas, que unifica o espírito e a matéria enquanto atividade dialética que resulta numa síntese que é a realidade social. Essa é a concepção de formação humana materialista desenvolvida por Marx que

tomando como ponto de partida do trabalho, considerado como ato ontológico-primário do ser social, constata que este ser não se define pela espiritualidade, mas pela práxis. Ora, esta última é exatamente uma síntese de espirito e matéria, de subjetividade e objetividade, de interioridade e exterioridade. Na realidade, ele mostra que entre interioridade e exterioridade não há uma relação de exclusão nem de soma, mas uma relação de determinação recíproca. Desta determinação recíproca é que resulta a realidade social (TONET, 2006, p. 11).

Assim, é a educação pensada/realizada desde conexões fundamentais na constituição histórica do ser humano: vida produtiva, cultura, história... (CALDART, 2015). Dessa forma, a formação humana que assumimos tem por base a integração de todas as dimensões da vida no processo formativo. Nesse aspecto, não está relacionada à formação geral ou específica, ou em outros termos, propedêutica ou profissionalizante. Mas "implica a integração das dimensões fundamentais da vida que estruturam a prática social" (RAMOS, 2008, p. 3-4).

Assim, a ênfase está no trabalho útil e seu princípio educativo é o trabalho real, na apropriação da ciência e do conhecimento, não no domínio do tecnicismo característica histórica da educação profissional. Não é a profissionalização estreita, o adestramento, o treinamento, a preparação para o mercado de trabalho - um dos fundamentos que sustentava a prática do ensino profissionalizante - a justaposição de disciplinas de formação geral e específica.

Tendo em sua base a perspectiva da educação para formação humana, a modalidade de educação profissional é expandida de modo que a centralidade do 
processo seja o sujeito e apropriação de todas as bases científicas que envolvem um determinado setor de produção - trabalho, ciência e tecnologia. Isso é fundamental para a emancipação do educando, pois possibilita a compreensão da relação entre trabalho, ciência e cultura como algo indissociável. Para Ramos (2008), significa compreender o trabalho como princípio educativo, o que não se confunde com o "aprender fazendo", nem é sinônimo de formar para o exercício do trabalho discurso e prática da profissionalização sob o capital. Para a autora, "considerar o trabalho como princípio educativo equivale dizer que o ser humano é produtor de sua realidade e, por isso, se apropria dela e pode transformá-la" (RAMOS, 2008, p. 4). É o entendimento que

ao integrar, por um lado, trabalho, ciência e cultura, tem-se a compreensão do trabalho como mediação primeira da produção da existência social dos homens, processo esse que coincide com a própria formação humana, na qual conhecimento e cultura são produzidos (CIAVATTA; RAMOS, 2012, p. 307).

Nesse viés, a proposta de ensino médio integrado à educação profissional que é defendida é uma opção política que se opõe ao ensino utilitário e particularista que tem como finalidade a manutenção das relações sociais vigentes. Ao contrário, tal proposta está calcada na perspectiva da politecnia ${ }^{5}$ e na formação omnilateral do educando que "incorpora valores ético-políticos, conteúdos históricos e científicos que caracterizam a práxis humana" (RAMOS, 2008, p. 5).

\section{O Processo de Implantação do Ensino Médio Integrado no Paraná}

Partimos do entendimento delineado por Frigotto (1999, 2011), Ciavatta (2009), Ramos (2008), no qual a educação media-se com o sistema social vigente numa relação dialética e contraditória, tensionada pelas relações de classe e por interesses antagônicos da classe trabalhadora e da burguesia. Assim, a educação profissional é determinada pelo capitalismo operante, mas, ao mesmo tempo, determina tal sistema, uma vez que, como campo de disputa, a classe trabalhadora intenta a busca de uma formação profissional voltada não só para trabalhar com as mãos, mas que vise a formação do educando em todos os sentidos. Isso é intrínseco à concepção de ensino integrado.

\footnotetext{
5"Refere-se a um sistema completo baseado no estudo da tecnologia em suas variadas formas, considerada do ponto de seu desenvolvimento e em todas as suas relações. Cobre o estudo da tecnologia natural [...] e a tecnologia dos materiais; o estudo dos implementos de produção e seus mecanismos; e o estudo da energia. Cobre também o estudo da base geográfica das relações econômicas, a influência dos métodos extrativos e de processamento sobre as formas sociais de trabalho e a influência dos últimos sobre a vida social em geral" (KRUPSKAYA, 1982, apud CALDART, 2012, p. 32).
} 
Assim, para compreender o pioneirismo que o estado do Paraná teve na discussão e implantação do ensino médio integrado ao ensino profissional, temos de voltar na história, trazendo o ordenamento no qual a educação profissional foi conduzida na década de 90. O principal instrumento de política educacional direcionada à formação profissional foi o Decreto no $2.208 / 97$, que reforçava a herança da dualidade do sistema educacional, pois criou matrizes curriculares e matrículas distintas ensino técnico/ensino médio. Conforme seu Art. 50, "a educação profissional de nível técnico terá organização curricular própria e independente do ensino médio, podendo ser oferecida de forma concomitante ou sequencial a este".

$\mathrm{Na}$ mesma direção seguia a profissionalização em nível básico. O principal instrumento foi o Plano Nacional de Formação (PLANFOR), que tinha como finalidade qualificar e requalificar jovens e trabalhadores para acompanharem as mudanças do mundo globalizado, independentemente de escolarização ${ }^{6}$, conforme o Art. $3^{\circ}$, inciso I do Decreto n. ${ }^{\circ}$ 2208/97. Não interessava, aqui, a formação de sujeitos autônomos e conscientes, mas tão somente o treinamento para o mercado de trabalho. 0 trabalho nessa perspectiva é desvirtuado, alienado, descolado da ciência e da tecnologia, é uma mercadoria.

Nessa base foi criado o Programa de Expansão da Educação Profissional (PROEP/MEC), que com aporte financeiro do Banco Interamericano de Desenvolvimento (BID), desmontou a rede pública de educação profissional, tanto em âmbito nacional quanto estadual, submetendo-a à lógica do mercado. No Paraná, consubstanciado pela cartilha nacional,

a política foi desativar os 1080 cursos profissionalizantes existentes até 1996, e instituir o Programa Expansão, Melhoria e Inovação do Ensino Médio (PROEM), que, como consequência, de longo e médio prazo, remeteu à iniciativa privada a formação profissional técnica de nível médio, inclusive com o uso de espaços das próprias escolas públicas (PARANÁ, 2006, p. 17).

A estrutura criada para "gerenciar" o ensino profissional no estado foi a Agência para o Desenvolvimento da Educação Profissional (PARANATEC). Nesse contexto contraditório é que, a partir de 2003, a Rede Estadual de Educação paranaense passou a retomar a discussão para a oferta da educação profissional integrada à educação básica, sendo uma das primeiras ações o encerramento das atividades dessa Agência e a criação do Departamento de Educação Profissional vinculada diretamente à Secretaria de Estado da Educação.

A partir de então, começou-se a delinear uma nova política de educação profissional que incorporava os anseios de educadores progressistas, os quais

\footnotetext{
${ }^{6}$ Grifos das autoras.
} 
defendiam que esta fosse pública, gratuita e integrada à educação básica desde sua concepção. Assim, foram realizados encontros, em 2003 e 2004, com professores e pesquisadores ${ }^{7}$ para discutir os principais aspectos legais, técnicos, pedagógicos e administrativos referentes a essa nova concepção de formação profissional que compreende a relação trabalho e educação na perspectiva de emancipação humana.

Juntamente com a política de reestruturação curricular, foi estabelecido: a) expansão da Rede de educação profissional e sua manutenção sem a cobrança de taxas de qualquer natureza; b) a instituição de quadro próprio de professores; c) a formação continuada do corpo docente e técnico; d) melhoria da estrutura física e material dos estabelecimentos escolares públicos.

A expansão da oferta da educação profissional, nessa concepção de ensino integrado, efetivou-se legalmente pelo Parecer no 1.028/03, do Conselho Estadual de Educação, que aprovou o Plano de Expansão de Educação Profissional para o ano de 2004. Já o Parecer no 1.095/03 validou as novas propostas curriculares elaboradas conjuntamente com professores, diretores, equipe pedagógica dos Núcleos Regionais de Educação de vários municípios paranaenses. No ano de 2004

o estado do Paraná iniciou cursos de educação profissional técnico de nível médio, com organização curricular integrada ao ensino médio, em 15 colégios que ofertam cursos do setor primário (área agropecuária/florestal); em cinco que ofertam cursos do setor secundário (área eletromecânica/química); em seis que ofertam cursos do setor terciário (área de comunicação e artes/informática/administração da confecção/meio ambiente) e nos 45 que ofertavam cursos na modalidade normal em nível médio para formar docentes da educação infantil e dos anos iniciais do ensino fundamental (PARANÁ, 2006, p. 19).

Importante destacar que tudo isso ocorreu na vigência do Decreto no 2.208/97, que além de separar a escolarização do ensino técnico, reforça a dualidade no ensino, seguir a orientação estreita de formação para o mercado de trabalho (trabalho tratado só na sua dimensão econômica), impossibilitava a destinação de recursos públicos para investimento em educação profissional nas instituições públicas, pois a defesa era que a formação profissional fosse predominantemente executada na esfera privada.

Daí o pioneirismo do estado do Paraná ao assumir, em nível estadual, outra concepção de ensino profissional e, ao mesmo tempo, expandir essa modalidade de ensino na perspectiva de integralidade com a educação básica que, como vimos

\footnotetext{
${ }^{7}$ Acácia Kuenzer, Domingos Leite, Gaudêncio Frigotto, Ivone Maria, Marize Ramos, Lucília Machado, entre outros.
} 


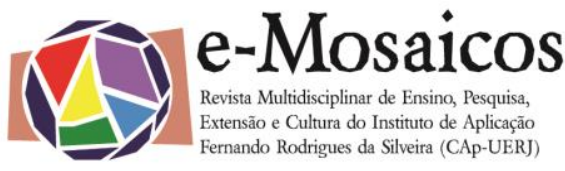

DOI: $10.12957 /$ e-mosaicos.2017.30263

anteriormente, tem compromisso com o educando, buscando uma formação que lhe propicie a apreensão dos conhecimentos científicos, tecnológicos, históricos e sociais.

Enfim, uma educação que forneça ao estudante elementos para compreender a realidade social em que está inserido. Só em julho de 2004, o Decreto no 5154, do governo federal, conferiu a legalidade à proposta curricular desenvolvida e já efetivada na Rede pública de Educação do Paraná.

\section{ELEMENTOS DA EDUCAÇÃo NO MST: BASES PARA A CONSTRUÇÃo DA PROPOSTA DOS COMPLEXOS DE ESTUDO}

A trajetória da educação no MST resultou da dinâmica evolutiva do próprio movimento. Conforme se ampliam as concepções, as relações, as estratégias dos sujeitos coletivos que o compõem, alteram-se, também, as discussões e as reinvindicações que se faz em relação à educação e à escola. Podemos ver, então, o movimento como um espaço de luta. Pois, além dele próprio possuir uma dimensão educativa, ainda possibilita pensar a educação de forma mais ampla. É um lugar singular para exercitar ações educativas que tenham por objetivo os princípios da formação humana e da educação politécnica para a classe camponesa.

Assim, as Escolas de Assentamento e Acampamento do MST, junto com as universidades públicas do Paraná, produziram no ano de 2013 uma proposta pedagógica alternativa, baseada na experiência dos educadores russos da Escola do Trabalho, sistematizada por Pistrak (2009 e 2011) e Shulgin (2013).

A proposta pedagógica Complexos de Estudo é o resultado da incorporação da experiência Russa da Escola do Trabalho, com todo o acúmulo de construções teóricas educativas do MST com Pedagogia do Movimento a partir dos Ciclos de Formação Humana. E apresenta como categoria principal o trabalho. Esta forma escolar visa "romper com a lógica da seriação e, consequentemente, de tempos homogêneos e de desenvolvimento e de aprendizagem" (BAHNIUK, CAMINI, 2012, p. 334), pois o desafio é tentar organizar uma escola onde a centralidade esteja no sujeito, que o trabalho pedagógico tenha um princípio educativo e os educandos possam compreender a realidade e atuar sobre ela. Ampliando-se em concepções que evidenciem caminhos para a construção de uma nova forma escolar, promovendo a auto-organização dos estudantes, construindo diferentes formas de autogestão.

Desse modo, inicia-se uma organização, a partir do coletivo estadual de educação do MST, junto com os coordenadores e alguns educadores das Escolas Itinerantes do estado, e também se juntaram especialistas das universidades. A assessoria principal foi dada por Luiz Carlos de Freitas ${ }^{8}$ (UNICAMP) e Roseli Salete

\footnotetext{
${ }^{8}$ Freitas é pesquisador de Pistrak e da Pedagogia Soviética, inicia suas pesquisas entre 1985-1987, as quais são a partir das discussões da década de 1980. O pesquisador tentava construir uma pedagogia
} 
Caldart ${ }^{9}$ (ITERRA/MST). Esse coletivo tem como tarefa escrever a proposta.

Foram definidos três níveis para a elaboração da proposta: do sistema (define o currículo e as ligações gerais com a vida e a abordagem metodológica geral), do coletivo escolar (que lidera a adequação das decisões tomadas ao nível do sistema ao entorno da escola, concreta) e de preparação do magistério (que precisa conhecer todo o sistema de produção dos complexos para poder aplicá-lo) (SAPELLI, 2015, p. 8).

Os Complexos de Estudos apresentam como concepção de educação a busca pela intencionalização da formação humana na perspectiva do desenvolvimento omnilateral dos sujeitos envolvidos no processo educativo, construindo, assim, vínculos com objetivos sociais, políticos e societário como projeto de humanidade. Não é apenas como instrutiva, mas busca promover o acesso ao conjunto da produção cultural de uma sociedade. Educação é uma ação planejada e organizada objetivamente. Ela é produzida por um coletivo de forma intencional, que propicia o desenvolvimento multilateral, atuando em diferentes dimensões. Nesse sentido,

complexo é uma construção teórica da didática socialista como um espaço onde se pratica a tão desejada articulação entre a teoria e prática, pela via do trabalho socialmente útil. Sendo "socialmente útil" acontece no meio e em contato com a natureza e com a sociedade, o que se articula com outras duas categorias vistas anteriormente: atualidade (a realidade tal qual se expressa no meio educativo e sua transformação) e a auto-organização (forma de se preparar sujeitos históricos). Não há, portanto, separação entre a atualidade, autoorganização, trabalho e complexo de estudo. O complexo é um espaço articulador dos três primeiros elementos (e não apenas um "tema") (FREITAS, 2011, p. 165).

Assim, essa concepção de educação somente é possível a partir de uma ruptura com a escola convencional promovendo uma mudança significativa na forma escolar, pois entendemos que objetiva-se à superação da matriz cognitiva. Dessa forma, torna-se necessário ampliar as discussões acerca do método materialista histórico dialético e alterar o conteúdo e a forma da escola.

que relacionasse o marxismo ao socialismo e, então, buscou elementos na Rússia por ser o país com maior discussão.

${ }^{9}$ Caldart é doutora em Educação pela Universidade Federal do Rio Grande do Sul (UFRGS), integrante do Setor de Educação do MST, da Articulação Nacional por uma Educação do Campo e do coletivo político-pedagógico do Instituto de Educação Josué de Castro/RS. 
Entende-se que a perspectiva de alterar a forma escolar pressupõe uma descentralização do processo educativo do espaço da sala de aula. Essa mudança busca vinculá-la a outros objetos formativos que estão na realidade concreta do espaço circundante da escola. "A realidade atual é tudo o que, na vida social da nossa época, está destinado a viver e a se desenvolver, tudo o que se agrupa em torno da revolução social vitoriosa e que serve a organização da vida nova" (PISTRAK, 2011, p.25).

As matrizes pedagógicas não estão centralizadas apenas no cognitivo, mas "exige formação mais ampla, o desenvolvimento da afetividade, da criatividade, do corpo, a habilidade de trabalhar coletivamente, de auto organizar-se enfim, o desenvolvimento pleno de todas as habilidades" (FREITAS, 2011, p. 166). Isso quer dizer, um trabalho humano associado ao processo educativo por meio das matrizes formativas: trabalho, luta social, organização coletiva, cultura e história.

Ao trabalhar na escola as matrizes formativas são elencadas, em primeira instância, as vivências do sujeito Sem Terra: a mística, a pertença, as marchas, os símbolos. E, em segunda instância, as vivências educativas, as formas de educar o sujeito que o compreenda como sujeito Sem Terra.

\section{ORganização pedagógica, Política e ADMINISTRATIVA da Escola nos CompleXos DE ESTUDO}

A prática educativa nos Complexos necessariamente tem que assumir as dimensões de resgatar a dignidade para construir uma identidade coletiva a partir de um projeto educativo que propicie a formação humana comprometida com a luta social. Assim, o trabalho pedagógico faz a articulação dos conteúdos com o objetivo de promover uma forma de ensinar que vai além da compreensão das regras básicas das ciências, fornecendo elementos para que o educando compreenda a vida por meio da natureza e da participação em sociedade. Assim, nos Complexos

o conteúdo da escola é preliminarmente o conteúdo da vida, do meio natural e social, sistematizado na forma de conceitos, categorias e procedimentos pelas ciências. No entanto tal conteúdo não está desprovido de lutas e contradições. Se o conteúdo expresso nas bases das ciências é o conteúdo da vida em um outro nível de elaboração, seu domínio pela juventude não pode se dar fora da vida, fora do meio sem considerar suas contradições. $E$ a vida não é o mesmo lugar em todo lugar. Não há como usar uma metodologia para padronizar e "empacotar" as contradições, as lutas e levá-las para "dentro da escola" com o objetivo de conscientizar o aluno fora da vida (FREITAS, 2011, p. 159). 
A forma de articular a organização pedagógica é uma maneira do estudante crescer envolvido em um movimento de luta, a partir da análise e da compreensão da conjuntura histórica em que está inserido, bem como a organização da sociedade, promovendo uma maneira de ensinar os estudantes a viver na atualidade.

O esquema abaixo organiza os fundamentos pedagógicos da escola e apresenta os elementos que compõem a proposta dos Complexos de Estudo e, ainda, estabelece as principais categorias e as possíveis relações, além de propor uma ruptura com a forma escolar convencional, relacionando e conectando a escola com a vida,

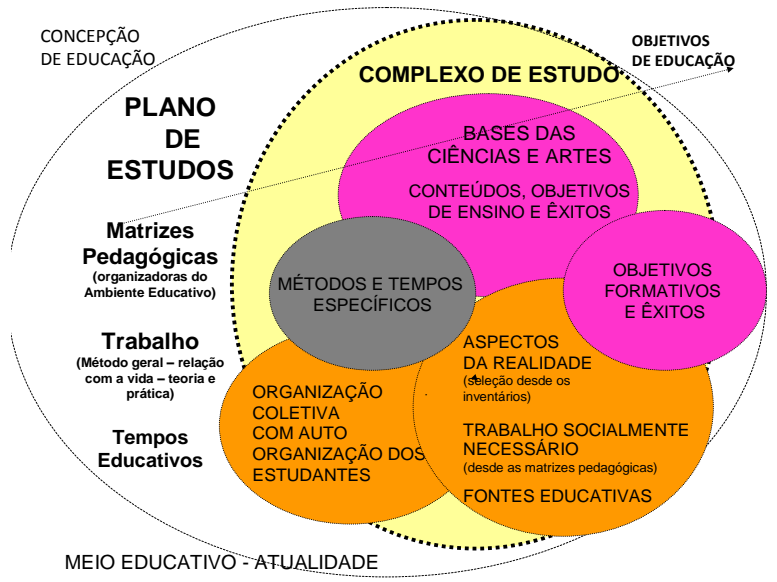

Fonte: MST $(2013$, p. 32)

É possível observar no esquema que os complexos identificam as fontes educativas dentro e no entorno do acampamento/assentamento. 0 que define 0 complexo é o trabalho como princípio educativo, o qual está na vida, nas bases das ciências e das artes, nas matrizes pedagógicas e nas organizações coletivas e na auto-organização dos estudantes.

O trabalho socialmente necessário deve envolver todas as matrizes pedagógicas, na escola e fora dela, devendo materializar sua conexão orgânica com a vida social do entorno da unidade escolar. "A construção de uma nova forma escolar inclui uma reflexão epistemológica ou sobre como as práticas educativas escolares devem trabalhar com a dimensão do conhecimento, e como essa dimensão integra o processo educativo mais amplo" (CALDART, 2011, p. 47).

Considerando que a forma escolar convencional está comprometida em sua constituição com as funções de exclusão e subordinação, a qual retrata a configuração histórica da época que vivemos, o documento síntese orientador da proposta da experimentação dos Complexos de Estudo aponta como a escola deve ser organizada politicamente, a auto-organização dos estudantes, conforme figura a 
seguir:

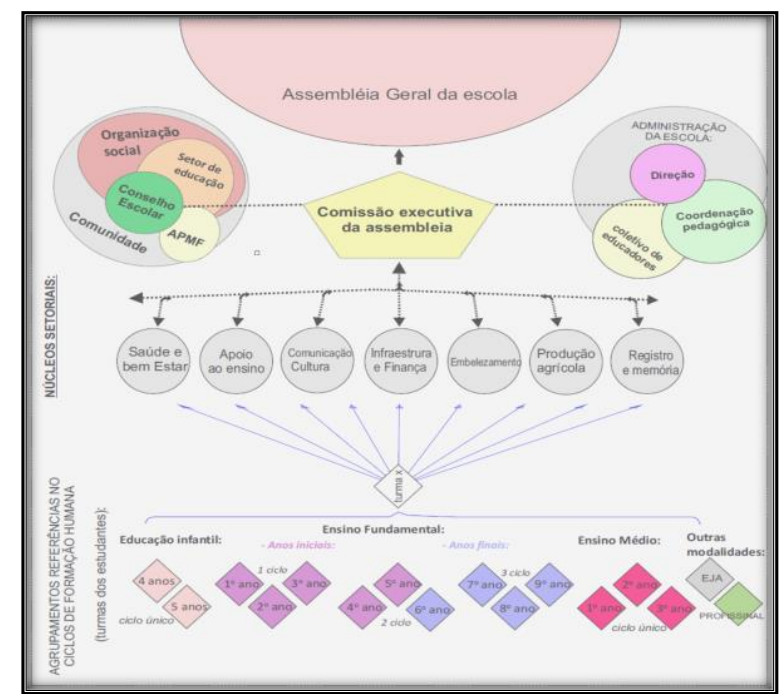

Fonte: MST (2013, p. 25)

Este esquema orienta uma gestão democrática e participativa por meio dos Núcleos Setoriais. As séries/anos estão organizadas por ciclos de formação humana, que tem na Assembleia a instância máxima da gestão, todos que pertencem à escola participam como membro e têm voz ativa. A comunidade é representada pela associação de pais, pelo conselho escolar, pela organicidade do acampamento. 0 acesso ao conhecimento está garantido e, igualmente, à vivência de novas relações no interior da escola e entre a escola e a vida.

Nesse âmbito a escola torna-se o centro cultural e de pesquisa do seu entorno. Os educadores e educandos têm que conhecer adequadamente a realidade em que estão inseridos, as possibilidades educativas, as fontes educativas, as lutas, a organização social e as formas de subsistência. E todas as relações sociais são intencionalmente educativas.

Nos Complexos, igual na concepção de ensino integrado, a categoria trabalho é entendida como articuladora do processo de formação, associada a dois importantes conceitos de auto direção e de atualidade, pois se deseja instrumentalizar os estudantes para alterar a sociedade capitalista, a qual expropria a força de trabalho da juventude. A intenção não é de que os estudantes apenas saibam ler, escrever, contar. Mas, sim, que tenham condições de ler e entender o mundo a partir de perspectiva crítica compreendendo a educação como formação humana, pois

a escola educa pelo trabalho quando busca no mundo do trabalho e da produção, uma das matérias primas para o estudo. Desde a infância, pode proporcionar contato com o mundo produtivo real 
como forma de incorporar valor social ao trabalho e refletir sobre a lógica da dimensão econômica. O trabalho não consiste em um momento específico, mas atravessa o conjunto das atividades da escola, por isso, à medida que se interliga às disciplinas e a todas as atividades da escola com intencionalidade, ele alcança seus objetivos educativos (RITTER; GREIN; SOLDA, 2015, p. 135).

Os Complexos de Estudo têm como matriz fundamental o trabalho e reúne um conjunto de todas as relações que movimentam e dão forma à escola que se quer construir, na intenção de fundamentar uma formação omnilateral, a partir da realidade do sujeito. O trabalho, bem explorado através dos conteúdos científicos e organizados nos espaços educativos, põe em evidência a dimensão e a exercitação da ação coletiva, além de congregar diversos conhecimentos na perspectiva da politecnia. Então, aprender a organizar-se coletivamente é um exercício que aproxima da vida real para dar conta da vida prática.

É uma escola que cria lutadores pelos ideais da classe operária, organizada pelos estudantes com ajuda de dirigentes com base no trabalho é conduzida pela vida e pela trajetória do desenvolvimento econômico; esta é a escola politécnica operária, que é a demonstração de que a sociedade burguesa está morrendo, que a classe construtora vem para substitui-la, que seus objetivos são os objetivos desta, e que ela os põe em prática (SHULGIN, 2013, p. 42).

Entende-se que o Complexo de Estudo não é um método de ensino, porém viabiliza a vinculação entre teoria e prática, através do trabalho socialmente necessário na escola. Um trabalho conectado com as áreas do conhecimento da proposta pedagógica busca a garantia dos objetivos da aprendizagem, onde os educandos olham o mesmo objeto de conhecimento na perspectiva dos diferentes componentes curriculares.

\section{CONSIDERAÇõEs Finais}

Ao concluirmos esta exposição, confirmamos que, tanto a proposta de ensino médio integral quanto os Complexos de Estudos - ambas pioneiras no estado do Paraná - têm a perspectiva de formação omnilateral do educando. Claro está, também, que ambas as propostas têm a categoria trabalho na sua dimensão ontocriativa que engendra o principio educativo, a ciência e a tecnologia, que possibilita a produção e reprodução da vida em sociedade.

De fato, no âmbito formal de ensino, a concepção de ensino médio à educação profissional na sociedade atual é condição necessária para a travessia em direção ao 
ensino médio politécnico e à superação da dualidade educacional, legado da sociedade de classe. Apesar de todos os limites que a materialidade da sociedade capitalista nos impõe, temos a utopia que se essa perspectiva for efetivamente inserida, teremos a transformação da estrutura social e a formação do educando em múltiplas dimensões.

Essa utopia parece mais próxima de ser alcançada pela proposta Complexos de Estudos, por ser uma proposta verdadeiramente política e contra-hegemônica que encontra liberdade no seio do MST para ser desenvolvida. Os Complexos externalizam uma educação de classe, mas da classe trabalhadora. Aqui a escola está balizada em três pilares: autogestão, auto-organização e trabalho social, eixos fundamentais para a construção de um novo cidadão, dono de seu saber e de suas escolhas.

Em momentos como o que estamos atravessando, de desmontes sociais, inclusive na perspectiva da educação integrada, faz-se necessário o debate por propostas educacionais que tenham em seu âmago a centralidade no ser humano. Assim, por mais que a realidade seja desalentadora para a classe trabalhadora, devemos seguir, como está fazendo o MST, na luta por uma educação para emancipação do gênero humano. É o que nos ensina Gramsci: "pessimismo da inteligência, otimismo da vontade" (GRAMSCI, 2001, p. 267).

\section{REFERÊNCIAS BIBLIOGRÁFICAS}

BRASIL. Decreto no 2.208, de 17 de abril de 1997. Regulamenta o parágrafo $2^{\circ}$ do art. 36 e os art. 39 a 42 da Lei n. 9.394, de 20 de dezembro de 1996, que estabelece as diretrizes e bases da educação nacional. Diário Oficial da União, Brasília, DF, 18 abr. 1997. p. 7760.

BRASIL. Decreto $n^{\circ} 5.154$, de 23 de julho de 2004. Regulamenta o $\S 20$ do artigo 36 e os arts. 39 a 41 da Lei n. 9.394, de 20 de dezembro de 1996, que estabelece as diretrizes e bases da educação nacional, e dá outras providências. Diário Oficial da União, Brasília, DF, 24 jul. 2004.

BAHNIUK Caroline. CAMINI, Isabela. Escola Itinerante. In: CALDART, Roseli S. Dicionário da Educação do Campo. Rio de Janeiro, São Paulo: Escola Politécnica de Saúde Joaquim Venâncio, Expressão Popular, 2012.

CALDART, Roseli Salete. Seminário: Educação Politécnica e Agricultura Camponesa. In CALDART, Roseli Salete; STEDILE, Miguel Enrique; DAROS, Diana (orgs). Caminho para a transformação da escola: agricultura camponesa, educação politécnica e escolas do campo. São Paulo: Expressão Popular, 2015. 
DOI: $10.12957 /$ e-mosaicos.2017.30263

Caminhos para a transformação da escola: Reflexões desde as práticas da licenciatura em Educação do Campo. São Paulo: Expressão Popular, 2011.

CIAVATTA, Maria; RAMOS, Marise. Ensino Médio Integrado. In CALDART, Roseli Salete; PEREIRA, Isabel Brasil; ALENTEJANO, Paulo; FRIGOTTO, Gaudêncio (Orgs). Dicionário da Educação do Campo. São Paulo: Expressão Popular, 2012.

CIAVATTA, Maria. Mediações históricas de trabalho e educação: gênese e disputas na formação dos trabalhadores. Rio de Janeiro: Lamparina, Faperj, CNPq, 2009.

FREITAS, Luiz Carlos de. A Escola Única do Trabalho. In: CALDART, Roseli Salete (Org.) Caminhos para a transformação da Escola: reflexões desde práticas da licenciatura em Educação do Campo. São Paulo: Expressão Popular, 2011.

FRIGOTTO, Gaudêncio. A produtividade da escola improdutiva: um (re) exame das relações entre educação e estrutura econômico-social e capitalista. São Paulo: Cortez, 1999.

- Os circuitos da história e o balanço da educação no Brasil na primeira década do século XXI. In: Revista Brasileira de Educação. Rio de Janeiro, ANPED, jan/abr. 2011, v. 16 n.46.

GRAMSCI, Antônio. Os intelectuais. O princípio educativo. In: Cadernos do cárcere. Vol. 2. Rio de Janeiro: Civilização Brasileira, 2001.

Movimento dos Trabalhadores Rurais Sem Terra. Plano de Estudos. Cascavel: Edunioeste, 2013.

PARANÁ. Diretrizes da Educação Profissional: Fundamentos políticos e pedagógicos. Disponível em http://www.educadores.diaadia.pr.gov.br/arquivos/File/diretrizes/ diretrizeducacao_profissional.pdf. Acesso em 18 de maio de 2017.

PISTRAK, Moisey. Fundamentos da Escola do Trabalho. Tradução: Daniel Aarão Reis Filho. São Paulo: Expressão Popular, 2011.

RAMOS, Marise. Concepção do ensino médio Integrado. Disponível em http://www.iiep.org.br/curriculo_integrado.pdf. Acesso em: 16 de maio de 2016.

RITTER. Janete, GREIN. Maria Izabel. SOLDA, Maristela. A Questão do Trabalho na Escola Itinerante. In: SAPELLI. M. L. S., FREITAS. L.C., CALDART. R. S. (Orgs.). Caminhos para a Transformação da Escola: organização do trabalho pedagógico nas escolas do campo: ensaio sobre Complexos de Estudo. São Paulo: Expressão Popular, 2015 
SAPELLI, Marlene Lucia Salete. Escola do Campo - espaço de disputa e de contradição: análise da proposta pedagógica das Escolas Itinerantes do Paraná e do Colégio Imperatriz Dona Leopoldina. Tese (Doutorado) - Faculdade de Educação, Universidade Federal de Santa Catarina, Florianópolis, 2013.

. De Paulo Freire a Pistrak. Disponível em:

http://coral.ufsm.br/sifedocregional/images/Anais/Eixo\%2008/Marlene\%20Lucia\%20 Siebert\%20Sapelli.pdf. Acesso: 03 de Julho de 2015.

SHULGIN, Viktor NikholaeVich. Rumo ao politecnismo. Tradução Alexey Lazarev e Luiz Carlos de Freitas. São Paulo: Expressão Popular, 2013.

TONET. Ivo. Educação e formação humana. In: Ideação. Foz do Iguaçu/PR. v. 8, no 9, 2006. 